\title{
A SURVEY OF LEARNING STYLES OF ENGINEERING STUDENTS
}

\author{
Terresa S. Ashford, Randa L. Shehab, Teri Reed Rhoads, Mary C. Court \\ School of Industrial Engineering \\ University of Oklahoma \\ Norman, OK 73019
}

\begin{abstract}
This study examined the learning styles of engineering students using the Index of Learning Styles (ILS) developed by Soloman and Felder (Soloman \& Felder, 2002), the Cognitive Styles Analysis (CSA) developed by Riding (Riding, 1991), and the Learning Style Inventory (LSI) developed by Kolb (Kolb, 1993). Thirty-five graduate and thirty-six undergraduate engineering students took each of the assessments. There was a strong preference for the visual category on the ILS, but an even split for the imagery/verbal dimension on the CSA. Scores were also evenly split on the active/reflective and sequential/global dimensions on the ILS. Another strong preference was seen for the analytic category on the CSA. On the LSI, most students' scores indicated a preference for the convergent category and no student scores were in the divergent category. An overview of each of the instruments as well as a summary of student learning needs for each of the dimensions is presented.
\end{abstract}

\section{INTRODUCTION}

The study of individual differences in learning style attempts to explain the differences in the way people acquire and assimilate new information. Many researchers have developed theories regarding the way people learn (Riding \& Cheema, 1991). Accordingly, a number of assessments have been created to categorize the learning styles of individuals. This research looks at the learning styles of engineering students using three assessments of learning style.

The categories contained within each of the assessments are similar in that they are cognitive-based, as opposed to measuring environmental preferences. Each assessment also is based on two or more dimensions of style. For each dimension, there are two categories in which there is not an inherent "rightness" or "wrongness" in either. Rather, each is a horizontal continuum that attempts to explain differences, not to judge abilities.

A brief overview of each of the three assessments is presented below.

\section{Index of Learning Styles (ILS)}

The Index of Learning Styles is the result of work by Felder and Silverman (Felder \& Silverman, 1988). The assessment measures four dimensions of learning style: intuitive/sensing, visual/verbal, active/reflective, and sequential/global.

The intuitive/sensing and visual/verbal dimensions attempt to explain the way a person understands new information. Intuitive learners look for underlying theories whereas sensing learners look for specific facts. Visual learners prefer pictures such as charts and diagrams or visual demonstrations, while verbal learners prefer that new information be presented in written or spoken words.

Active learners prefer to be actively involved in learning new information by doing, testing, etc. Reflective learners understand best after having time to think about, or reflect, on the material presented. The sequential/global dimension refers to the preferred order of processing new information as it is learned. Global learners need to have the big picture presented to them, whereas sequential learners prefer information be presented in an organized, step-by-step manner.

The Index of Learning Styles contains 44 selfevaluative questions. Respondents are asked to choose between two options as to which is more applicable to themselves. For example, one question reads: "I would rather be considered a) realistic or b) innovative," (Felder, 2002).

The Index of Learning Styles is currently under development by Felder and Soloman. The authors caution that although the assessment is widely used, it has not yet been validated and should not be used to predict "suitability or unsuitability for a particular subject, discipline, or profession," (Felder, 2002).

\section{Cognitive Styles Analysis (CSA)}

Riding (1991) presents a computer-based assessment of cognitive style that measures wholist/analytic and 
verbal/imagery dimensions. According to Riding and Rayner (1998), the cognitive styles of individuals affect how they learn through preferences in material format, concept structure, material presentation, and content.

The wholist/analytic dimension includes aspects of several other learning style theories, including field dependence vs. field independence, holist vs. serialist, and impulsivity vs. reflectivity, among others (Riding \& Cheema, 1991). Field dependence/independence was first introduced by Witkin (1962), and describes a person's ability to see individual parts of a total. Holist vs. serialist was first introduced by Pask and Scott (1972) and describes a person's strategy for understanding complex material by either approaching the task with a step-by-step method or by scanning for patterns in the overall material. Impulsivity vs. reflectivity was introduced by Kagan (1965) and describes a person's tendency to make decisions either slowly or quickly and with more or fewer errors. Therefore, the wholist learning style is one that sees the whole of a situation, whereas the analytic learning style focuses on the specific parts (Riding, Dahraei, Grimley and Banner, 2001)

The verbal/imagery dimension of the Cognitive Styles Analysis defines the process by which information is represented once it is learned. Verbal representations are in the form of either words or sounds. Imagery representations take the form of scenes or pictures.

As an assessment instrument, the Cognitive Styles Analysis does not require a meta-cognitive analysis from the respondents. Rather, it scores responses and response times to a series of questions. High scores determine learning style on the wholist/analytic element of the assessment whereas response times are used to categorize learners on the verbal/imagery dimension. However, a low score does not indicate a preference for the opposite end of the continuum. The authors formatted the assessment in this way to avoid inaccurate categorizations of style based on testing discrepancies (e.g., non-responses by the participant).

Specifically, the wholist/analytic dimension is measured by presenting pairs of figures. The respondent is then asked to judge their similarity. Wholistic styles would score high on these questions. The CSA also measures the wholist/analytic dimension using geometric line drawings, which may or may not have a more simple drawing embedded within. Analytic thinkers are more likely to find the embedded shape if it exists (Riding, 1991).

Verbal-imagery style is assessed by the response time needed to answer true /false questions about pairs of words. The questions ask whether the words are of the same "type" or of the same "color." Assuming correct answers, people with a verbal orientation will have a faster response time for the "type" pairs while a person who uses imagery to represent information will respond faster to the "color" pairs.

Riding and colleagues report high validity and high reliability with the CSA instrument (Riding \& Rayner, 1998).

\section{Learning Style Inventory (LSI)}

Kolb's Learning Style Inventory assesses perception and processing styles of individuals. Perception refers to information intake, either through concrete experience (CE) or abstract conceptualization (AC). Processing refers to the way new information is assimilated with prior knowledge either through reflective observation (RO) or active experimentation (AE). Kolb combines the styles on the two continuums to create the accommodative $(\mathrm{CE}+\mathrm{AE})$, divergent $(\mathrm{CE}$ $+\mathrm{RO})$, convergent $(\mathrm{AC}+\mathrm{AE})$, and assimilative $(\mathrm{AC}+$ RO) styles seen in Figure 1. (Kolb, 1984)

The traits of the accommodative learning style include a need for getting involved in the learning experience. It is called accommodative due to the ability of learners in this category to adapt to new and different learning situations. By contrast, the learners in the assimilative learning style are able to create theories and learn best while thinking abstractly (Kolb, 1984).

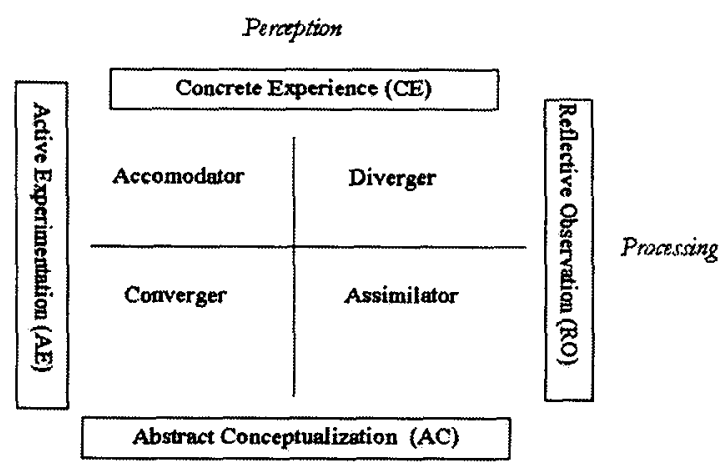

Figure 1. Kolb's learning styles (adapted from Kolb, 1984).

The strengths of divergent learners include the ability to see multiple perspectives of a situation. Divergers are particularly adept at brainstorming activities. In comparison, convergent learners use theoretical knowledge to solve specific problems. Deductive reasoning is a trait seen in this learning style. 
The Learning Style Inventory consists of 12 selfevaluative questions in which respondents are asked to rank sets of statements according to their perception of how applicable the statements are to themselves. For example, "I learn by: feeling_, doing _, watching _, or thinking_" (Kolb, 1993). Curry (1983) reported strong reliability with the original LSI instrument but only moderate validity.

As opposed to other theories of learning style, Kolb asserts that in any given learning experience, individuals move through each of the learning styles. However, it should be noted that use of the Kolb model by other researchers is in the format of learning 'styles' that are fairly static to the individual (Fandelova, 1999, Sharp, 2001, Papp, 2001).

\section{PROBLEM DEFINITION}

The goal of this research was to identify the learning styles of a cross-section of engineering students in order to guide future engineering instruction. Data was collected from both graduate and undergraduate engineering students to see if there was a difference in learning needs. Multiple assessments were used to increase the perspective gained from the study. The particular assessments used were chosen both for widespread acceptance in the field of learning/cognitive styles and for the similarity in the authors' descriptions of the dimensions.

\section{METHOD}

\section{Participants}

Thirty-six undergraduate and thirty-five graduate engineering students volunteered to participate in this study. Participants ranged in age from 19-51 years (median of 23), and $24 \%$ were female. Participants were not compensated for their time, but were provided with the results of their learning style assessments.

\section{Procedure}

Participants took each of the three assessments (ILS, CSA and LSI) either in partitioned desks in a learning lab or during regularly scheduled class periods. The order in which participants completed the assessments was randomly assigned. Both the Index of Learning Styles and Learning Styles Inventory were pen and paper assessments. The Cognitive Styles Analysis was computer-based. Laptop computers were set up in the cubicles or classrooms and students rotated through the assessments at their own pace. After the participants were finished, they received the results of their learning styles and an explanation of what the learning styles mean according to the respective author.

\section{RESULTS}

In general, the results across the three assessments describe the majority of engineering students as visual, sensing, analytic and convergent. The results from each of the assessments are shown in Table 1, and are discussed below.

\section{Index of Learning Styles}

The engineering students showed a strong difference in the visual/verbal dimension for the Index of Learning Styles. Seventy-nine percent of participants were in the visual category, while only $21 \%$ were in the verbal category. Another strong difference was seen in the sensing/intuitive dimension. Seventy percent of participants were in the sensing category whereas only $30 \%$ were in the intuitive. The active/reflective dimension was almost evenly split at $49 \%$ and $51 \%$, respectively. There was a slight difference in results for the sequential/global dimension. Fifty-nine percent of participants were sequential, whereas only $41 \%$ were global.

Results for class standing for the Index of Learning Styles followed the same trends as the overall results in all but one dimension. The active/reflective dimension was opposite for undergraduates and graduates. Fiftyfour percent of graduate students were in the reflective category whereas $53 \%$ of undergraduates were in the active category.

\section{Cognitive Styles Analysis}

The results of the Cognitive Styles Analysis indicated a balanced distribution of participants across the verbal/imagery dimension. Forty-nine percent of engineering students evaluated were categorized as imagers whereas $51 \%$ were categorized as verbal. Participants exhibited a stronger difference along the analytic/wholist dimension. Seventy-two percent of the engineering students were in the analytic category and $28 \%$ were wholist.

The differences between class of students were not very strong. Both undergraduate and graduate students were evenly distributed between imagers and verbalisers. Results for the analytic/wholist dimension followed the same trends as the overall scores in that 
more of the engineering students scored as analytic than wholist. Sixty-seven percent of undergraduate and $77 \%$ of graduate students were analytic.

\section{Learning Style Inventory}

The results of the Learning Style Inventory for engineering students showed a preference toward the convergent category. Fifty-six percent of students were convergers, whereas $31 \%$ were assimilators and only $13 \%$ were in the accommodators. None of the engineering students were found to be divergers.

Scores of engineering students divided by class standing showed similar results. Undergraduate and graduate students both showed a definite preference for the convergent category, $50 \%$ and $63 \%$, respectively. Results for the assimilative category were the same for undergraduate and graduate students at $31 \%$ each. A stronger difference was seen in the accommodative category. Nineteen percent of undergraduate students but only $6 \%$ of graduate students were accomodators.

Table 1. Percentages of engineering students in each dimension of the Cognitive Styles Analysis (CSA), Learning Styles Inventory (LSI), and Index of Learning Styles (ILS).

\begin{tabular}{|l|l|c|c|c|} 
Assessment & \multicolumn{1}{l}{ Dimensions } & Total & Undergraduate & Graduate \\
\hline \multirow{4}{*}{} & Visual & 79 & 78 & 80 \\
\cline { 2 - 5 } & Verbal & 21 & 22 & 20 \\
\cline { 2 - 5 } & Sequential & 59 & 56 & 63 \\
\cline { 2 - 5 } & Global & 41 & 44 & 37 \\
\cline { 2 - 5 } & Intuitive & 30 & 31 & 29 \\
\cline { 2 - 5 } & Sensing & 70 & 69 & 71 \\
\cline { 2 - 5 } & Active & 49 & 53 & 46 \\
\cline { 2 - 5 } & Reflective & 51 & 47 & 54 \\
\hline
\end{tabular}

\begin{tabular}{l|l|l|l|l|}
\hline \multicolumn{1}{c|}{ CSA } & 49 & 50 & 49 \\
\hline \multirow{1}{*}{ Imagery } & 51 & 50 & 51 \\
\cline { 2 - 5 } & Verbal & 72 & 67 & 77 \\
\hline Analytic & 28 & 33 & 23 \\
\hline
\end{tabular}

\begin{tabular}{|l|c|c|c|}
\hline \multirow{4}{*}{ Ascomodative } & 13 & 19 & 6 \\
\hline Divergent & 0 & 0 & 0 \\
\hline Assimilative & 31 & 31 & 31 \\
\hline Convergent & 56 & 50 & 63 \\
\hline
\end{tabular}

\section{DISCUSSION}

An interesting artifact of this study was the difference between scores on the visual/verbal dimension on the ILS and the imagery/verbal dimension on the CSA. Scores on this dimension were evenly split on the CSA, whereas there was a strong preference for the visual category on the ILS. The difference between the students placing into the visual or verbal categories on these two assessments may be due to the difference in formats. The ILS asks specific self-evaluative questions whereas the CSA interprets true/false responses to a pair of words. Because the CSA measures response time as well as responses, participants whose first language is one other than English may be at a disadvantage since it may take them longer to recall definitions of unfamiliar vocabulary. The sample population did include a large number of international students whose native language was not English. Although the CSA is available in several different languages, it was not practical to license multiple versions of the software. Furthermore, it was felt that participants would have a working knowledge of the English language due to the requirements of the university's admission policies.

In 2001, Sharp reported that over 10 years of data collection, scores of engineering students fell into all four categories of Kolb's LSI. However, there was continually a majority of students in the convergent and assimilative categories, with accommodators and divergers consistently ranking $3^{\text {rd }}$ and $4^{\text {th }}$, respectively. This study found the same pattern of results.

\section{ACCOMODATING LEARNING STYLES}

Felder and Henriques (1995) relate that a mismatch between student learning style and method of information presentation results in a reduction of test scores and possibly increased dropout rates. However, accommodating learning styles need not be difficult. To that end, a list of learning needs, as shown in Table 2, was compiled.

As an example, the majority of students were in the visual category on the ILS, but the majority of college instruction is in a verbal format either through lectures or written text. Incorporating graphics or other visual aids where possible, would help to accommodate those students.

Sometimes adding one component to a lecture can accommodate several categories of learning style. For example, sequential and analytic learners will perform better when information is provided in a step-by-step manner, while global and wholist learners need to understand the big picture in order to see where the individual parts fit in. In order to accommodate both of these styles, as well as active, sensing, and concrete experience learners, an instructor could begin a lecture 
with a story problem (which provides a 'big picture' as well as a concrete example) and then refer back to the story when components of the lecture relate to aspects of the problem (which provides a step-by-step problem solving example).

Table 2. Strategies for teaching to the learning styles of students. Adapted from Felder (1993, 1998) and Clark (2003).

\begin{tabular}{|c|c|c|}
\hline $\begin{array}{l}\text { Assessment } \\
\text { Instrument }\end{array}$ & Style & Learning Needs \\
\hline CSAILS & Analytic/Sequential & $\begin{array}{l}\text { Logical flow } \\
\text { Step-by-step examples }\end{array}$ \\
\hline CSAILS & Wholist/Global & $\begin{array}{l}\text { Overall goal } \\
\text { Real world examples } \\
\text { Connections with other } \\
\text { relevant material }\end{array}$ \\
\hline CSAILS & Imagery Nisual & $\begin{array}{ll}\text { Plots } \\
\text { Graphic } \\
\text { Demonstrations } \\
\text { Diagrams/pictures }\end{array}$ \\
\hline CSAILS & Verbal & $\begin{array}{l}\text { Text or audio explanations } \\
\text { and derivations }\end{array}$ \\
\hline LSI/ILS & $\begin{array}{l}\text { Concrete } \\
\text { Experience/ } \\
\text { Sensing }\end{array}$ & \begin{tabular}{|l|} 
Descriptions of physical \\
phenomena (problems) \\
first \\
- Results from experiments \\
Demonstrations, numerical \\
examples \\
Trigger films
\end{tabular} \\
\hline LSI/ILS & $\begin{array}{l}\text { Abstract } \\
\text { Conceptualization/ } \\
\text { Intuitive }\end{array}$ & $\begin{array}{l}\text { Theories, models and } \\
\text { material that emphasizes } \\
\text { fundamental understanding } \\
\text { Algebraic examples } \\
\text { Analogies }\end{array}$ \\
\hline LSI/ILS & $\begin{array}{l}\text { Reflective } \\
\text { Observation/ } \\
\text { Reflective }\end{array}$ & $\begin{array}{l}\text { Time to reflect upon what } \\
\text { is being learned } \\
\text { "What's wrong with this? } \\
\text { exercises }\end{array}$ \\
\hline LSI/ILS & $\begin{array}{l}\text { Active } \\
\text { Experimentation/ } \\
\text { Active }\end{array}$ & $\begin{array}{l}\text { Problem-solving exercises } \\
\text { in class } \\
\text { Games } \\
\text { Simulations }\end{array}$ \\
\hline
\end{tabular}

\section{FUTURE RESEARCH}

The authors are currently investigating the correlation between scores on the respective instruments in both engineering and non-engineering disciplines, with the hope of identifying redundancies between the test instruments. In addition, the authors intend to determine which, if any, of these dimensions is crucial to accommodate when designing for computer-mediated education. It is hoped that a better understanding of student differences in learning style will encourage better accommodation of the differences in the classroom.

\section{ACKNOWLEDGEMENTS}

This research was funded by the College of Engineering at the University of Oklahoma.

\section{REFERENCES}

Clark, D. R. (2003). Kolb's Learning Style Inventory. Retrieved February $10^{\text {th }}$ from

www.nwlink.com/ donclark/hrd/learning/styles.html\#kolb

Curry, L. (1983). An organization of learning styles theory and constructs. Annual Meeting of the American Educational Research Association (ERIC Document No. 235 185).

Felder, R.M. (1993). Reaching the Second Tier: Learning and Teaching Styles in College Science Education. Journal of College Science Teaching, 23 (5), 286-290.

Felder, R.M. \& Henriques, E.R. (1995). Learning and teaching styles in foreign and second language education. Foreign Language Annals, 28 (1), 21-31.

Felder, R. M., and Silverman, L.K. (1988). Learning and Teaching Styles in Engineering Education. Engineering Education, 78 (7), 674-681.

Kagan, J. (1965). Individual differences in the resolution of response uncertainty. Journal of Personality and Social Psychology, 2 (2), 154-160.

Kolb, D.A. (1993). Learning Style Inventory. [Assessment]. (Available from Hay/Mcber, Boston MA)

Kolb, D. A. (1984). Experiential Learning: Experience as the source of learning and development. Englewood Cliffs, NJ: Prentice Hall, Inc.

Papp, R. (2001). Student learning styles and distance education. In Proceedings of the $16^{\text {th }}$ Annual Conference of the International Academy for Information Management.

Pask, G. and Scott, B. C. E. (1972). Learning strategies and individual competence. International Journal of Man-Machine Studies, 4 (3), 217-253.

Riding, R. J. (1991). Cognitive Styles Analysis. [Assessment]. (Available from Learning and Training Technology, Harborne, Birmingham, UK).

Riding, R. J., \& Cheema, I. (1991). Cognitive styles: An overview and integration. Educational Psychology, 11, 193-215.

Riding, R. J., Dahraei, H., Grimley, M. \& Banner, G. (2001). Working memory, cognitive style and academic attainment. In R. Nata (Ed.) Progress in Education (Vol.5). New York: Nava Science Publishers, Inc.

Riding, R. J., \& Rayner, S. (1998). Cognitive Styles and Learning Strategies: Understanding style differences in learning and behaviour. London: D. Fulton Publishers.

Sadler-Smith, E. (2001). A reply to Reynold's critique of learning style. Management Learning, 32 (3): 291-304.

Sharp, J. E. (2001). Teaching teamwork communication with Kolb learning style theory. In Proceedings of the 31st Annual Conference of the American Society for Engineering Education/IEEE Frontiers in Education (F2C).

Soloman, B.A. \& Felder, R.M. (2002). Index of Learning Styles. [Assessment]. (Available from R. Felder, http://www.ncsu.edu/felder-public/ILSpage.html)

Witkin, H.A. (1962). Psychological Differentiation: Studies in Development. New York: Wiley. 